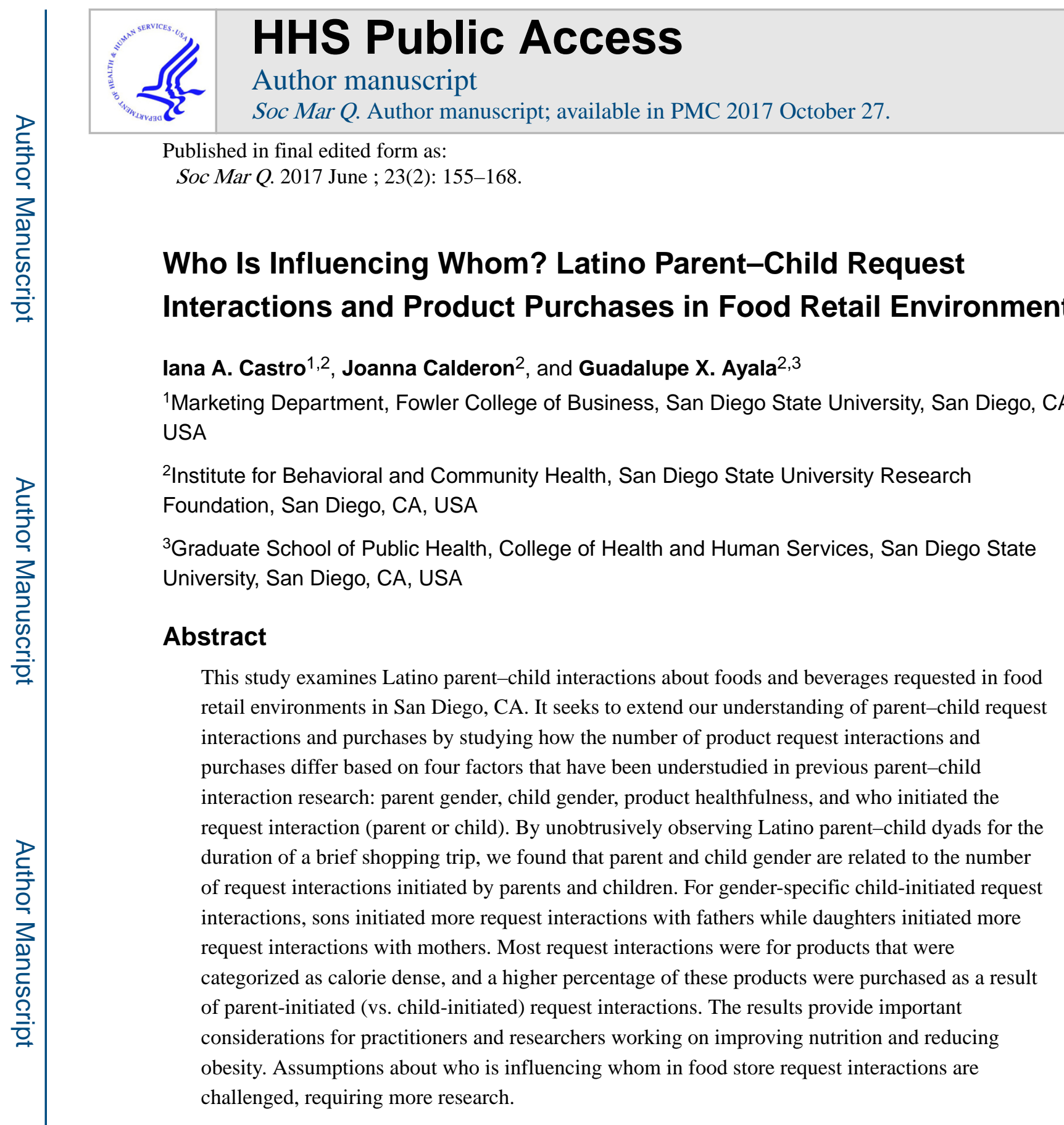

\title{
Keywords
}

health; nutrition; obesity

Reprints and permission: sagepub.com/journalsPermissions.nav

Corresponding Author: Iana A. Castro, Marketing Department, College of Business Administration, San Diego State University, 5500 Campanile Dr., MC 8236, San Diego, CA 92182, USA. iana.castro@mail.sdsu.edu.

The National Institutes of Health had minimal involvement in study implementation and was not involved in writing the manuscript and the decision to submit the manuscript for publication.

Declaration of Conflicting Interests

The author(s) declared no potential conflicts of interest with respect to the research, authorship, and/or publication of this article. 
Grocery shopping is a routine consumer behavior in the United States (U.S.). Even though U.S. consumers are increasingly relying on away-from-home foods, U.S. consumers visit grocery stores an average of 1.6 times/week (Food Marketing Institute, 2014). Among some racial/ethnic groups, grocery shopping occurs almost daily, as is the case for Latino consumers (Ayala, Baquero, Laraia, Ji, \& Linnan, 2013; Ayala, Mueller, Lopez-Madurga, Campbell, \& Elder, 2005). Latinos are the fastest-growing racial/ethnic population in the United States (U.S. Census Bureau, American Fact Finder, 2008-2012) and are disproportionately impacted by obesity (Ogden, Carroll, Kit, \& Flegal, 2014). Forty-two percent of Latino adults and 22\% of Latino children aged 2-19 years are obese compared with 33\% and 14\% of non-Hispanic White adults and children, respectively (Ogden et al., 2014). Furthermore, compared with non-Hispanic shoppers, Latino consumers coshop more frequently (29\% vs. $23 \%$ ), most often with children (Unilever, 2005), and have a $50 \%$ greater likelihood of being influenced by children (ConAgra Foods, 2011).

When parents shop with their children, there are many opportunities for bidirectional attempts to influence decisions (Murphy, Ice, McCartney, Leary, \& Cottrell, 2012; Skouteris et al., 2012). Children can influence purchase decisions by asking parents to purchase a product (Atkin, 1978; Buijzen \& Valkenburg, 2008; Ebster, Wagner, \& Neumueller, 2009; Flurry \& Burns, 2005; Gaumer \& Arnone, 2009; Nadeau \& Bradley, 2012; Valkenburg \& Cantor, 2001). Parents can also influence purchases by initiating request interactions and asking their children if they would like a product (Atkin, 1978; Buijzen \& Valkenburg, 2008; Gaumer \& Arnone, 2009). Parent-child interactions surrounding foods and beverages requested, whether child initiated or parent initiated, have important implications for products purchased and health outcomes. One study found that parents who shop with children spent an average of $31 \%$ more money and $11 \%$ more time in the store than those shopping alone (Thomas \& Garland, 1993). Purchases, in turn, influence what children consume (Ayala et al., 2007), which is a significant contributor to obesity (Howarth, Murphy, Wilkens, Hankin, \& Kolonel, 2006; Huang, Roberts, Howarth, \& McCrory, 2012; Ledikwe et al., 2006; McCrory et al., 1999). Foods and beverages purchased in grocery stores account for a significant portion of the total daily energy intake and, for children, are the most important source of empty calories, added sugar, and solid fats compared with schools and fast-food restaurants (Drewnowski \& Rehm, 2013; Poti, Slining, \& Popkin, 2013). Given that grocery shopping plays a significant role in dietary intake (Booth et al., 2001) and diet quality (Hersey et al., 2001), this exploratory study examines Latino parentchild interactions about foods and beverages requested in food stores to provide a more complete conceptualization of these request interactions and purchase outcomes. The study was conducted in San Diego, CA, which is a large, ethnically diverse community located on the U.S.-Mexico border. Estimates indicate that $32 \%$ of the county's population is Latino (U.S. Census Bureau, American Fact Finder, 2008-2012), making it an ideal location to study Latino consumers.

\section{Conceptual Development}

This study was informed by the intersection of two theories relevant to parent-child request interactions, social cognitive theory (SCT; Bandura, 1986) and family systems theory (FST; Broderick, 1993). SCT suggests that aspects of the person (e.g., gender) and the physical and 
social environments (in this case, dyads in a food store) intersect to influence behaviors (Bandura, 1986). FST acknowledges that there are subsystems within families that must be recognized in order to understand behaviors. Among the most widely studied subsystem is the parent-child relationship (Skelton, Buehler, Irby, \& Grzywacz, 2012), with evidence supporting their reciprocal influence (Gibson, Wardle, \& Watts, 1998). This study builds on these theories by considering the reciprocal influence of parents and children while shopping in food stores. Such studies are needed, given that health-related decisions occur in many contexts with implications for lifelong health habits and their consequences.

Research specific to parent-child request interactions in retail environments has used selfreport and observational approaches to identify factors that influence child-initiated requests. These include how the request was made (e.g., just asks, begs, and pleads; Atkin, 1978; Ebster et al., 2009; Gaumer \& Arnone, 2009; Nadeau \& Bradley, 2012), coshopping frequency (Ebster et al., 2009; Grossbart, Carlson, \& Walsh, 1991), child movement restriction (Ebster et al., 2009; Rust, 1993), monthly house-hold income, and child age (Ebster et al., 2009). The focus of our research is on four factors that are understudied: parent gender, child gender, requested product healthfulness (i.e., nutrient vs. calorie density of a product; $\mathrm{CATCH} \AA$, 2002), and who initiated the request interaction (i.e., parent or child).

Most parent-child interaction studies have focused mainly (Atkin, 1978; Buijzen \& Valkenburg, 2008; Darian, 1998; Ebster et al., 2009; Nadeau \& Bradley, 2012) or exclusively on mothers (Galst \& White, 1976; Holden, Ritchie, \& Coleman, 1992). The focus on mothers has created a gap in the literature on how fathers interact with their children in consumer settings. Family roles and responsibilities have changed as men account for more than $40 \%$ of those responsible for grocery shopping (Food Marketing Institute, 2014). Men are becoming increasingly involved in food shopping and preparation, and this trend is notable among Latino families (Arredondo, Elder, Ayala, Slymen, \& Campbell, 2006; Flagg, Sen, Kilgore, \& Locher, 2013; Harnack, Story, Martinson, Neumark-Sztainer, \& Stang, 1998). Additionally, fathers are spending more time with their children (Bianchi, 2000; Yeung, Sandberg, Davis-Kean, \& Hofferth, 2001). Therefore, parent gender should be considered. Furthermore, most studies have not looked at the effects of child gender while others have found no effect (e.g., Gaumer \& Arnone, 2009). The current study considers parent gender and child gender to determine whether the number of parent-child request interactions initiated and products purchased differ based on parent and child gender.

Additionally, research on who initiated the request interaction and products purchased is limited, with most studies focusing on child-initiated request interactions and suggesting that parents (vs. children) initiate fewer request interactions when grocery shopping but that these request interactions are more likely to result in a product purchase (Atkin, 1978; Buijzen \& Valkenburg, 2008). However, research has not addressed requested and purchased product healthfulness. Product healthfulness should be considered since children are unlikely to request a product they perceive as healthy, given the negative attributions made about the taste of healthy foods (Carruth, Ziegler, Gordon, \& Barr, 2004; Harris, 2008). One study that looked at the types of products children requested found that $55 \%$ of all childinitiated request interactions were for unhealthy, sweet, and savory products (O'Dougherty, 
Story, \& Stang, 2006). Furthermore, product healthfulness may impact the likelihood of the parent agreeing to purchase a product requested by a child, as a parent is unlikely to buy or suggest a product that he or she does not want the child to eat. Therefore, further research into requested product healthfulness and who initiated the request interaction is warranted. Our research extends prior research on parent-child interaction by studying whether the number of parent-child request interactions initiated and products purchased differ based on the healthfulness of the product requested and who initiated the parent-child request interaction.

\section{Method}

Data were collected as part of a larger parent-child mixed-methods study (Calderon et al., 2016). The data used in this research were collected during entry interviews and unobtrusive observations conducted with parent-child dyads recruited from three similar limited assortment food stores that catered to Latino consumers in San Diego, CA. Limited assortment food stores are smaller food stores that carry fewer product categories and fewer options within each product category compared to supermarkets (Levy \& Weitz, 2012). The three stores had two to three cash registers, four to five walkways, shopping carts with child seats, and produce, serviced meat, serviced prepared foods, and serviced bakery departments.

Study eligibility criteria included (a) adult at least 18 years of age, (b) identified as Latino, (c) purchased food products at the store where the data were being collected, (d) adult was parent of child, (e) child was between 3 and 14 years of age (similar to previous studies; Atkin, 1978; Buijzen \& Valkenburg, 2008; Ebster et al., 2009; Gram, 2010), (f) adult lived with the child at least 4 days/week (to confirm parent influence over the child's diet), and (g) adult had not participated in the same study in past weeks. Three hundred and sixteen adultchild dyads were approached as they entered the stores and 182 (58\%) were screened for eligibility (the rest refused), 104 (57\%) were eligible, 1 refused, and 3 became ineligible after consent due to a third-person joining the dyad, so 100 dyads participated.

After obtaining verbal informed consent, the adult completed an entry interview. Variables captured during the entry interview of interest here included shopping trip purpose, parent age and gender, and child age and gender. After completing the interview, the dyads entered the store and completed their shopping trip. Unobtrusive observations of the dyads were conducted from the time they entered the store until they exited. Unobtrusive observations in the natural context provide more objective information than survey and interview-based selfreports, given that the decision-making process is not always rational, and people tend to over or underestimate influences on decision-making, particularly the degree of child influence (Ebster et al., 2009; Gram, 2010; Turk \& Bell, 1972). Parents were told that observations were taking place inside the store, so they may be observed; however, steps were taken to reduce the visibility of the observers by incorporating them into the store environment, with one observer posing as a customer (Ebster et al., 2009; Nadeau \& Bradley, 2012) and one posing as a store employee (Atkin, 1978; Gaumer \& Arnone, 2009). 
Each of the observers completed structured observation forms recording the parent-child request interactions. A request interaction consisted of a conversation between a parent and child regarding a desired/offered product. Variables captured by the observers included observation length, number of request interactions initiated, who initiated each request interaction, the product requested, and whether the product was purchased (coded as yes if the parent/child agreed to a product purchase and the item was placed in the cart/basket, carried for purchase, or parent agreed nonverbally [e.g., nods]; coded as no if parent/child refused/declined the item or the parent had no reaction to the child's request). Based on 11 parent-child dyad observations co-coded by two observers (based on convenience of dual observations), overall interrater reliability using the percentage of agreement was $89 \%$. At the completion of the unobtrusive observation, adults completed an exit interview (not addressed in this study).

The We Can! guidelines were used to categorize products into three categories on a continuum from nutrient dense to calorie dense: go products (almost anytime foods, on the nutrient-dense side of the continuum), slow products (sometimes foods, in the middle of the nutrient-dense to calorie-dense continuum), and whoa products (once in a while foods, on the calorie-dense side of the continuum; CATCH®, 2002). Three raters with expertise in nutrition and one study coauthor were given a handout that explained the We Can! guidelines and provided examples of foods and beverages for each category across multiple food groups. Raters independently categorized the products into one of the three categories or selected "unknown" as a category if the appropriate categorization was not clear. Intraclass correlation coefficients were .66 (estimate of reliability for a single rater) and .89 (estimate of reliability for multiple raters). Products were placed in a category if at least three of the raters agreed on a categorization. Eleven percent of products requested were not placed in a category due to lack of agreement between raters, $7 \%$ could not be categorized because the observer did not capture sufficient information about the product, and 5\% were categorized as unknown, leaving 112 of the 144 products requested categorized as go, slow, or whoa products.

\section{Analyses and Results}

First, we present dyad, shopping trip, and parent-child interaction characteristics. Second, we examine the effects of parent and child gender on the number of parent-initiated and child-initiated request interactions and purchases. Finally, we explore the relationship between the healthfulness of the product requested, the person initiating the request interaction (parent or child), and whether or not the requested product was purchased.

\section{Dyad, Shopping Trip, and Parent-Child Request Interaction Characteristics}

Table 1 presents descriptive statistics for child, parent, dyad, shopping trip, and parent-child request interaction characteristics. The parents' average age was 38 years and $60 \%$ were female. The children's average age was 8 years and $49 \%$ were girls. Thirty-six percent of the dyads were mother-daughter dyads, $24 \%$ were mother-son dyads, $27 \%$ were father-son dyads, and $13 \%$ were father-daughter dyads. 
The average observation length was 10.2 min per dyad, and observations ranged from 2 to $55 \mathrm{~min}$. Eighty-three percent of the participants indicated that the purpose of their trip was a quick trip (as opposed to fill-in, major stock-up, and special purpose). The purpose of the quick trip is to obtain a few necessary items (Food Marketing Institute, 2012; SymphonyIRI Group, 2011; Unilever, 2005). The number of request interactions that occurred between the dyads ranged from 0 to 6 , with 0 occurring in $32 \%$ of dyads. Parent-initiated request interactions ranged from 0 to 3 , and $73 \%$ of dyads did not have any parent-initiated interactions. Child-initiated request interactions ranged between 0 and 5 , and $43 \%$ of dyads did not have any child-initiated interactions. A total of 144 request interactions were observed and 58\% (84) resulted in a purchase. Twenty-four percent of all request interactions (35) were parent initiated and 66\% (23) resulted in a purchase. Seventy-six percent (109) of all request interactions were child initiated with 56\% (60) resulting in a purchase.

\section{Number of Parent-Child Request Interactions and Products Purchased by Parent and Child Gender}

Descriptive statistics-Figure 1 shows descriptive statistics for all parent-child request interactions and purchases observed by who initiated the request interaction and parent and child gender. Children initiated $76 \%$ of parent-child request interactions. In child-initiated request interactions, sons initiated more request interactions than daughters $(59 \%$ vs. $41 \%$, respectively), and a higher percentage of the products they requested were purchased (63\% vs. $44 \%$, respectively). Sons initiated more request interactions with fathers than daughters, and a higher percentage of the products sons (vs. daughters) requested from fathers were purchased. Daughters initiated more request interactions with mothers than sons, but a higher percentage of the products sons (vs. daughters) requested from mothers were purchased (see Figure 1).

In parent-initiated request interactions, fathers initiated more request interactions than mothers, and a higher percentage of the products they requested were purchased. Fathers initiated more request interactions with sons than with daughters, but a higher percentage of products were purchased as a result of request interactions with daughters than with sons. Mothers initiated more request interactions with daughters than with sons, but a higher percentage of products were purchased as a result of request interactions with sons (vs. daughters; see Figure 1).

Analyses-Given that each dyad could have multiple interactions, the first interaction for each of the dyads was analyzed to ensure independence of observations (see Figure 2).

Seventy-one percent of the request interactions were child initiated. A crosstab did not reveal a significant difference between child-versus parent-initiated request interactions resulting in purchase (Figure 2, Column A).

A crosstab with who initiated the request interaction (parent or child) and parent gender was marginally significant and suggested that children initiated more request interactions with mothers than with fathers while for parent-initiated request interactions, fathers initiated 
more request interactions with children than mothers, $\chi^{2}(1,68) 3.49, p .06$ (see Figure 2, Column B).

For child-initiated request interactions, a crosstab for the number of request interactions based on parent and child gender suggests that sons initiated more request interactions with fathers while daughters initiated more request interactions with mothers (Fisher's exact test, $p<.001$; see Figure 2, Column C). Differences in purchases in child-initiated request interactions based on parent and child gender and differences for the number of request interactions or purchases based on parent and child gender for parent-initiated request interactions could not be analyzed due to small sample sizes (see Figure 2, Column C).

\section{Number of Parent-Child Request Interactions and Products Purchased by Product Healthfulness and Who Initiated the Request Interaction}

Descriptive statistics-Figure 3 shows descriptive information for all parent-child request interactions and purchases observed by product healthfulness and who initiated the request interaction. The majority of products requested were categorized as whoa products (calorie dense), followed by slow products (in the middle of the calorie-dense to nutrientdense continuum) and go products (nutrient dense). Requests for slow products resulted in the most purchases (80\%), followed by whoa products (62\%) and go products $(42 \%)$.

Children (vs. parents) initiated more request interactions for products in all three categories, and child-initiated requests for go products and slow products resulted in more purchases than parent-initiated requests; however, parent-initiated requests for whoa products resulted in more purchases than child-initiated requests.

Analyses-Figure 4 shows 68 independent parent-child request interactions and purchases by product healthfulness and who initiated the interaction. A crosstab with product healthfulness (go, slow, whoa) and who initiated the request interaction was not significant (adult initiated: $29 \%$ go products, $14 \%$ slow products, and 57\% whoa products; child initiated: $7 \%$ go products, $12 \%$ slow products, and $81 \%$ whoa products). A crosstab with product healthfulness (go, slow, whoa) and product purchase (yes, no) was not significant. Finally, a crosstab with who initiated the request interaction (parent, child) and product purchase (yes, no) was conducted to determine whether more purchases resulted from parent-or child-initiated request interactions for whoa products (sample sizes for go and slow products were too small for further analyses). The results were significant, with more parentinitiated (vs. child-initiated) request interactions for whoa products resulting in purchase (Fisher's exact test, $p<.05$ ).

\section{Discussion}

The goal of this study was to extend previous research on parent-child request interactions in food retail environments to develop a greater understanding of how four understudied factors - child gender, parent gender, product healthfulness, and who initiated the request interaction (parent or child) - were related to the number of parent-child request interactions initiated and resulting product purchases. Our results make a number of important contributions to the literature, uncover important implications for future work focused on 
encouraging healthier decision-making in stores, and provide fruitful avenues for future research.

This study contributes to the literature in a number of ways. First, we show that parent and child gender should be considered when studying parent-child request interactions about food and beverage products in food stores. When children initiated the request interactions, sons initiated more request interactions with fathers while daughters initiated more request interactions with mothers. Additionally, we found a marginally significant effect that suggests that children initiated more request interactions with mothers, but fathers initiated more request interactions with their children. This is novel, given the lack of data on parentinitiated request interactions and on parent-child request interactions with fathers. Given the changing roles of men and fathers (Flagg et al., 2013; Food Marketing Institute, 2014; Harnack et al., 1998), this research takes an important first step in showing that Latino fathers interact differently with their children than mothers in food store environments. Most family-based interventions focus on modifying mothers' parenting behaviors within the home and modifying aspects of the home environment to support a healthy lifestyle (Golan, Weizman, Apter, \& Fainaru, 1998). These findings suggest that the interpersonal sources of influence within food stores (Glanz, Sallis, Saelens, \& Frank, 2005) are a necessary target for future interventions. Given that decisions about what foods and beverages are brought into the home are made in other contexts such as food stores, and given the important role that fathers play in children's feeding (Khandpur, Blaine, Fisher, \& Davison, 2014), these research findings can contribute to the design of innovative, contextually relevant, familybased interventions.

In terms of product healthfulness, the majority of products discussed were calorie-dense products. Given that past research has focused primarily on child-initiated request interactions, our results suggesting that product healthfulness did not differ based on who initiated the request interaction are somewhat unexpected. In addition, we found that product healthfulness and who initiates the request interaction may have an effect on whether or not the product is purchased. This finding has implications for the development of contextually relevant interventions that strive to modify how parents and children interact to support a healthy lifestyle.

Finally, this study focused on Latino consumers. Latino consumers exhibit different grocery shopping behaviors than non-Hispanic White consumers (ConAgra Foods, 2011; Unilever, 2005) and are faced with higher rates of adult and childhood obesity (Ogden et al., 2014). This study extends previous research on parent-child request interactions in grocery stores by involving an understudied Latino sample and conducting the research in Latino food stores.

\section{Limitations and Future Research}

This research improves our understanding of the parent-child request interactions that occur in food stores and has implications for public health, parenting, and marketing research. A number of limitations provide interesting avenues for future research. One limitation was the small sample size, which limited the analyses that could be conducted. A larger sample 
would allow the examination of child development, parenting and feeding strategies, and general shopping behaviors, such as frequency of food store visits and role as household primary or secondary food shopper, on purchasing behavior. These factors could be important in understanding the gender differences that emerged between fathers and mothers for the number of parent-child request interactions. Furthermore, a larger sample would allow for comparisons between purchases for parent-initiated and child-initiated requests in all product healthfulness categories. Collecting data on all of the products purchased during the shopping trip, the characteristics of products discussed (e.g., frequently purchased or special requests), and parental knowledge regarding product healthfulness of the products discussed and purchased would provide a greater understanding of why products are discussed and how they contribute to the overall foods purchased. Additionally, differences between Latino consumers and non-Hispanic White consumers on all of these factors could be a fruitful avenue for future research.

Our research focused on limited assortment food stores, which carry fewer products than conventional supermarkets, and most trips were classified as quick trips. Future research could determine whether the effects would differ in a conventional supermarket; perhaps being exposed to a different mix of products and a longer shopping duration could result in more request interactions for slow or go products.

Furthermore, the majority of purchase decisions are made in the store (Inman \& Winer, 1998), and parents and children are making food purchasing decisions jointly. Future research could study how sources of influence in the store environment, such as product placement and in-store promotions, influence parent-child request interactions and products purchased.

\section{Acknowledgments}

The authors thank Ms. Julie Pickrel and the research assistants for their invaluable assistance in carrying out this study.

\section{Funding}

The author(s) disclosed receipt of the following financial support for the research, authorship, and/or publication of this article: This study was funded by a Research Supplement to Promote Diversity in Health-Related Research to the second author (3R01CA140326-04S1) through the National Cancer Institute funded El Valor de Nuestra Salud study under the direction of the third author (R01CA140326).

\section{References}

Arredondo E, Elder J, Ayala G, Slymen D, Campbell N. Association of a traditional vs shared meal decision-making and preparation style with eating behavior of Hispanic women in San Diego County. Journal of the American Dietetic Association. 2006; 106:38-45. [PubMed: 16390665]

Atkin CK. Observations of parent-child interaction in supermarket decision-making. Journal of Marketing. 1978; 42:41-45.

Ayala GX, Baquero B, Arredondo EM, Campbell N, Larios S, Elder JP. Association between family variables and Mexican American children's dietary behaviors. Journal of Nutrition Education and Behavior. 2007; 39:62-69. [PubMed: 17346653]

Ayala GX, Baquero B, Laraia BA, Ji M, Linnan L. Efficacy of a store-based environmental change intervention compared with a delayed treatment control condition on store customers' intake of fruits and vegetables. Public Health Nutrition. 2013; 16:1953-1960. [PubMed: 23561842] 
Ayala GX, Mueller K, Lopez-Madurga E, Campbell NR, Elder JP. Restaurant and food shopping selections among Latino women in Southern California. Journal of the American Dietetic Association. 2005; 105:38-45. [PubMed: 15635343]

Bandura, A. Social foundations of thought and action: A social cognitive theory. Englewood Cliffs, NJ: Prentice Hall; 1986.

Bianchi SM. Maternal employment and time with children. Dramatic change or surprising continuity? Demography. 2000; 37:401-414. [PubMed: 11086567]

Booth SL, Sallis JF, Ritenbaugh C, Hill JO, Birch LL, Frank LD, Hays NP. Environmental and societal factors affect food choice and physical activity: Rationale, influences, and leverage points. Nutrition Reviews. 2001; 59:S21-S39. [PubMed: 11330630]

Broderick, C. Understanding family process: Basics of family systems theory. Newbury Park, CA: Sage; 1993.

Buijzen M, Valkenburg PM. Observing purchase-related parent-child communication in retail environments: A development and socialization perspective. Human Communication Research. 2008; 34:50-69.

Calderon J, Ayala G, Elder J, Belch GE, Castro IA, Weibel N, Pickrel JL. What happens when parents and children go grocery shopping? An observational study of Latinos in Southern California. Health Education \& Behavior. 2016 Advance online publication.

Carruth B, Ziegler P, Gordon A, Barr S. Prevalence of picky eaters among infants and toddlers and their caregivers' decisions about offering a new food. Journal of the American Dietetic Association. 2004; 104:S57-S64. [PubMed: 14702019]

CATCH1®. Coordinated approach to child health, 4th grade curriculum. Hasbrouck Heights, NJ: The Regents of the University of California and FlagHouse; 2002.

ConAgra Foods. The Hispanic food shopper: New insights for growth. 2011. Retrieved from http:// www.hispanicretail360.com/userfiles/file/2012\%20Presentations/Concurrent\%20Session \%20D-1\%20-\%20CAG_Hispanic\%208\%2014\%2012\%20Final\%20less\%20video.pdf

Darian JC. Parent-child decision making in children's clothing stores. International Journal of Retail and Distribution Management. 1998; 26:421-428.

Drewnowski A, Rehm CD. Energy intakes of US children and adults by food purchase location and by specific food source. Nutrition Journal. 2013; 12:59. [PubMed: 23656639]

Ebster C, Wagner U, Neumueller D. Children's influence on in-store purchases. Journal of Retailing and Consumer Services. 2009; 16:145-154.

Flagg L, Sen B, Kilgore M, Locher J. The influence of gender age education and household size on meal preparation and food shopping responsibilities. Public Health Nutrition. 2013; 17:1-10.

Flurry LA, Burns AC. Children's influence in purchase decision: A social power theory approach. Journal of Business Research. 2005; 58:593-601.

Food Marketing Institute. US grocery shopper trends 2012: Executive summary. Arlington, VA: Author; 2012.

Food Marketing Institute. US grocery shopper trends 2014. Arlington, VA: Author; 2014.

Galst JP, White MA. The unhealthy persuader: The reinforcing value of television and children's purchase-influencing attempts at the supermarket. Child Development. 1976; 47:1089-1096.

Gaumer CJ, Arnone C. Grocery store observation: Parent-child interaction in family purchases. Journal of Food Products Marketing. 2009; 16:1-18.

Gibson EL, Wardle J, Watts CJ. Fruit and vegetable consumption, nutritional knowledge and beliefs in mothers and children. Appetite. 1998; 31:205-228. [PubMed: 9792733]

Glanz K, Sallis J, Saelens B, Frank L. Healthy nutrition environments: Concepts and measures. American Journal of Health Promotion. 2005; 19:330-333. [PubMed: 15895534]

Golan M, Weizman A, Apter A, Fainaru M. Parents as the exclusive agents of change in the treatment of childhood obesity. American Journal of Clinical Nutrition. 1998; 67:6.

Gram M. Self-reporting vs. observation: Some cautionary examples for parent/child food shopping behaviour. International Journal of Consumer Studies. 2010; 34:294-399.

Grossbart S, Carlson L, Walsh A. Consumer socialization and frequency of shopping with children. Journal of the Academy of Marketing Science. 1991; 19:155-163. 
Harnack L, Story M, Martinson B, Neumark-Sztainer D, Stang J. Guess who's cooking? The role of men in meal planning, shopping, and preparation in US families. Journal of the American Dietetic Association. 1998; 98:995-1000. [PubMed: 9739799]

Harris G. Development of taste and food preferences in children. Current Opinion in Clinical Nutrition \& Metabolic Care. 2008; 11:315-319. [PubMed: 18403930]

Hersey J, Anliker J, Miller C, Mullis RM, Daugherty S, Dasa S, Thomas O. Food shopping practices are associated with dietary quality in low-income households. Journal of Nutrition Education. 2001; 33:S16-S26. [PubMed: 12857541]

Holden GW, Ritchie KL, Coleman SD. The accuracy of maternal self-reports: Agreement between reports on a computer simulation compared with observed behaviour in the supermarket. Early Development and Parenting. 1992; 1:109-119.

Howarth NC, Murphy SP, Wilkens LR, Hankin JH, Kolonel LN. Dietary energy density is associated with overweight status among five ethnic groups in the multiethnic cohort study. Journal of Nutrition. 2006; 136:2243-2248. [PubMed: 16857848]

Huang TT, Roberts SB, Howarth NC, McCrory MA. Effect of screening out implausible energy intake reports on relationship between diet and BMI. Obesity Research. 2012; 13:1205-1217.

Inman, J., Winer, R. Where the rubber meets the road: A model of in-store consumer decision making. Cambridge, MA: Marketing Science Institute; 1998.

Khandpur N, Blaine R, Fisher J, Davison K. Fathers' child feeding practices: A review of the evidence. Appetite. 2014; 78:110-121. [PubMed: 24667152]

Ledikwe JH, Blanck HM, Kahn LK, Serdula MK, Seymour JD, Tohill BC, Rolls BJ. Dietary energy density is associated with energy intake and weight status in US adults. The American Journal of Clinical Nutrition. 2006; 83:1262-1368.

Levy, M., Weitz, BA. Retailing management. 8th. New York, NY: McGraw-Hill; 2012.

McCrory MA, Fuss PJ, McCallum JE, Yao M, Vinken AG, Hays NP, Roberts SB. Dietary variety within food groups: Association with energy intake and body fatness in men and women. The American Journal of Clinical Nutrition. 1999; 69:440-447. [PubMed: 10075328]

Murphy E, Ice C, McCartney K, Leary J, Cottrell L. Is parent and child weight status associated with decision making and physical activity opportunities? Appetite. 2012; 59:563-569. [PubMed: 22732569]

Nadeau J, Bradley M. Observing the influence of affective states on parent-child interactions and instore purchase decisions. Journal of Consumer Behaviour. 2012; 11:105-114.

O'Dougherty M, Story M, Stang J. Observations of parent-child co-shoppers in super markets: Children's involvement in food selections, parental yielding and refusal strategies. Journal of Nutrition Education and Behavior. 2006; 38:183-188. [PubMed: 16731454]

Ogden CL, Carroll MD, Kit BK, Flegal KM. Prevalence of childhood and adult obesity in the United States, 2011-2012. The Journal of the American Medical Association. 2014; 311:806-814. [PubMed: 24570244]

Poti JM, Slining MM, Popkin BM. Where are kids getting their empty calories? Stores, schools, and fast-food restaurants each played an important role in empty calorie intake among US children during 2009-2010. Journal of the Academy of Nutrition and Dietetics. 2013

Rust L. Observations: Parents and children shopping together: A new approach to the qualitative analysis of observational data. Journal of Advertising Research. 1993; 33:65-70.

Skelton JA, Buehler C, Irby MB, Grzywacz JG. Where are family theories in family-based obesity treatment? Conceptualizing the study of families in pediatric weight management. International Journal of Obesity (London). 2012; 36:891-900.

Skouteris H, McCabe M, Ricciardelli LA, Milgrom J, Baur LA, Aksan N, Dell'Aquila D. Parent-child interactions and obesity prevention: A systematic review of the literature. Early Childhood Development and Care. 2012; 182:153-174.

SymphonyIRI Group. The CPG basket: Fostering growth in a time of conservation. Chicago, IL: Author; 2011.

Thomas A, Garland R. Supermarket shopping lists: Their effect on consumer expenditure. International Journal of Retail and Distribution Management. 1993; 21:8-14.

Turk JL, Bell NW. Measuring power in families. Journal of Marriage and Family. 1972; 34:215-222. 
Unilever. Trip management: The next big thing. 2005. Retrieved from: http://www.unileverusa.com/ Images/Unilever_Trip\%20Management_tcm23-4100.pdf

U.S. Census Bureau, American Fact Finder. American Community Survey 5-year: Estimates for San Diego County, CA. 2008-2012. Retrieved from http://factfinder2.census.gov/

Valkenburg PM, Cantor J. The development of a child into a consumer. Journal of Applied Developmental Psychology. 2001; 22:61-72.

Yeung WJ, Sandberg JF, Davis-Kean PE, Hofferth SL. Children's time with fathers in intact families. Journal of Marriage and Family. 2001; 63:136-154.

\section{Biographies}

Iana A. Castro is an Assistant Professor of Marketing in the Fowler College of Business at San Diego State University. She is also a Core Investigator at the Institute for Behavioral and Community Health.

Joanna Calderon earned a Master of Public Health degree at San Diego State University.

Guadalupe X. Ayala is Associate Dean for Research for the College of Health and Human Services at San Diego State University, Director of the Institute for Behavioral and Community Health, and Professor in the Graduate School of Public Health. 


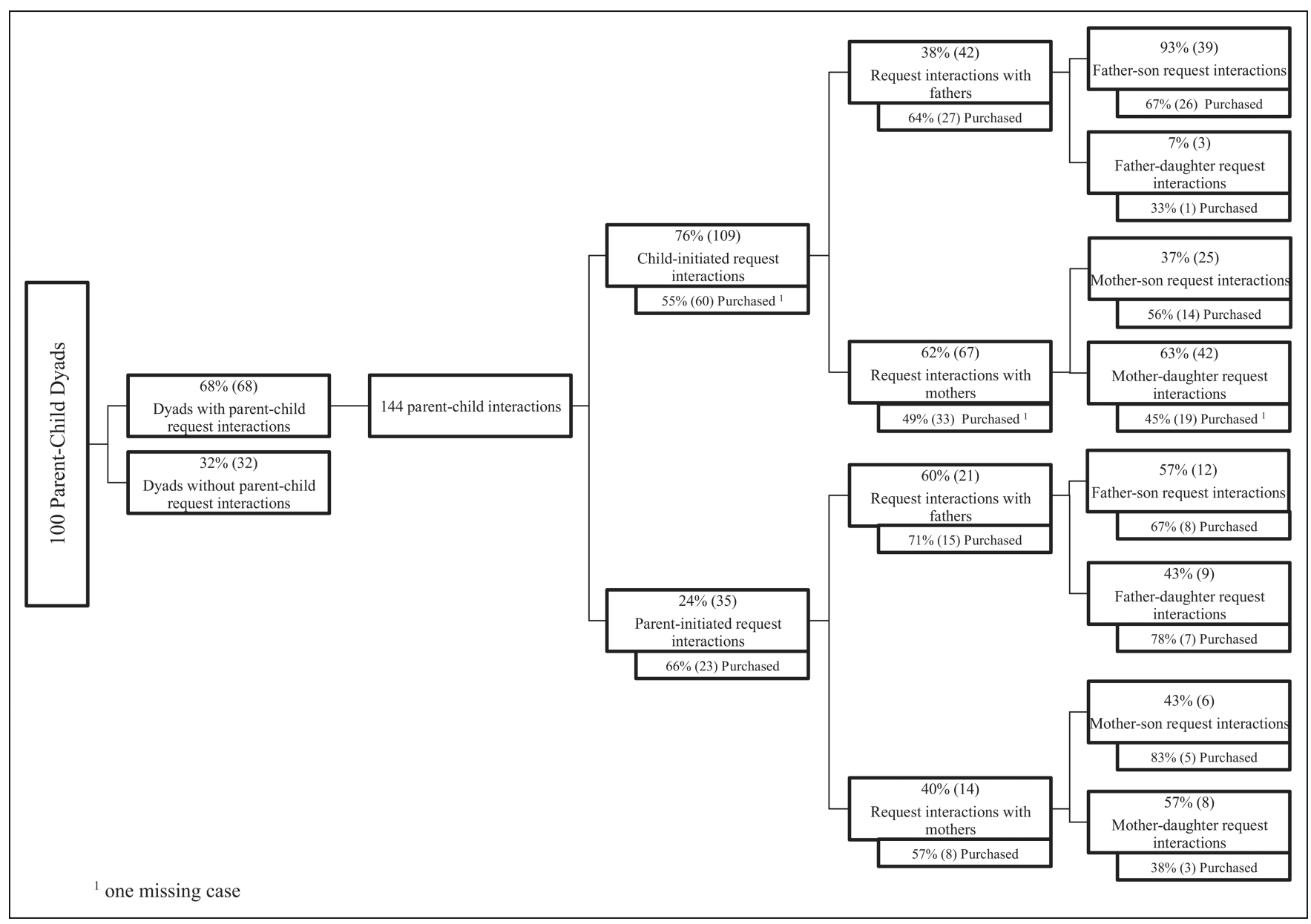

Figure 1.

All parent-child request interactions and purchases by who initiated the request interaction, parent gender, and child gender. Superscript 1 represents one missing case.

Note. It should be noted that what is being reported is \% (n). 


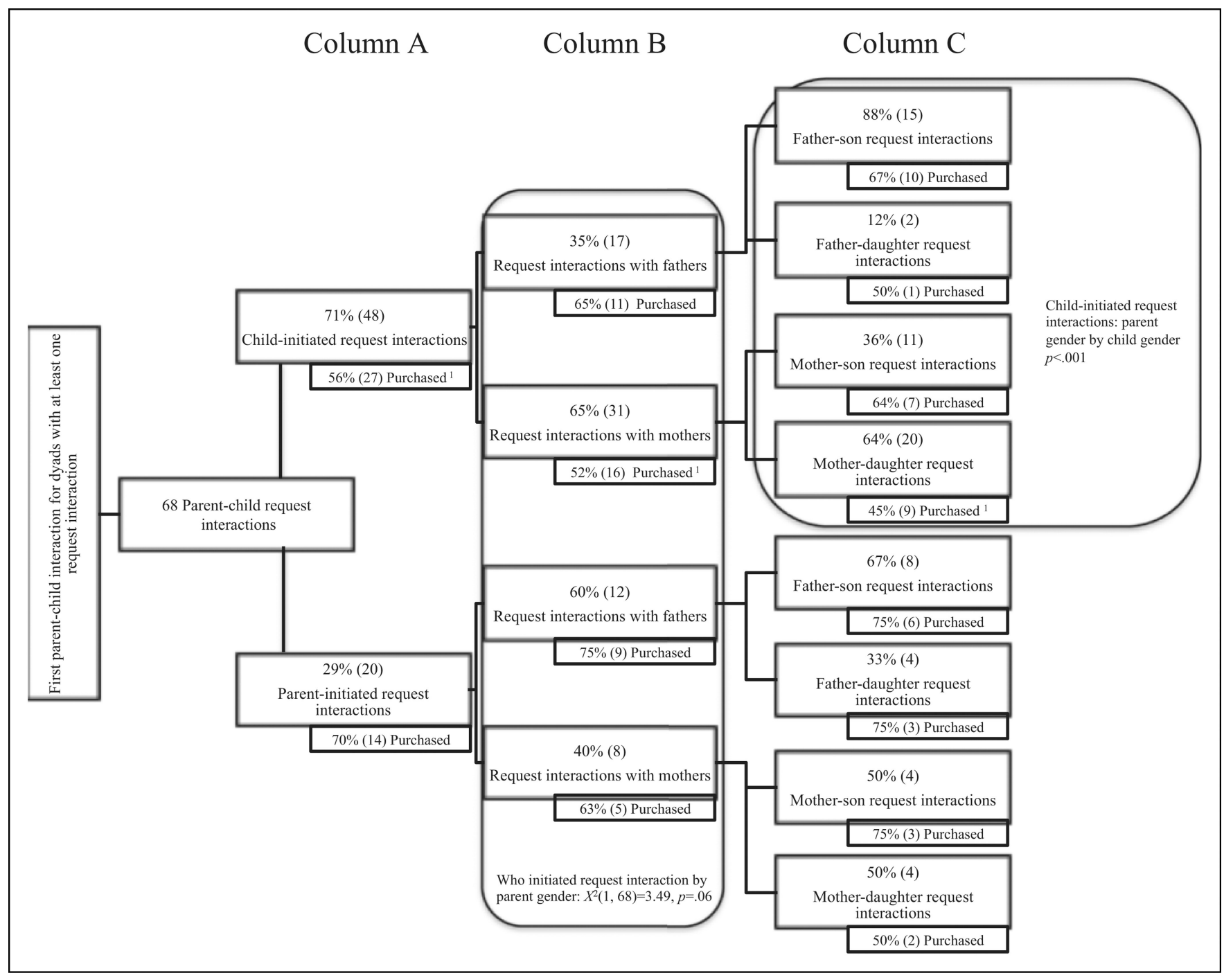

Figure 2.

Independent parent-child request interactions and purchases by who initiated the request interaction, parent gender, and child gender.

Note. ${ }^{1}$ Represents one missing case. It should be noted that what is being reported is \% (n). 


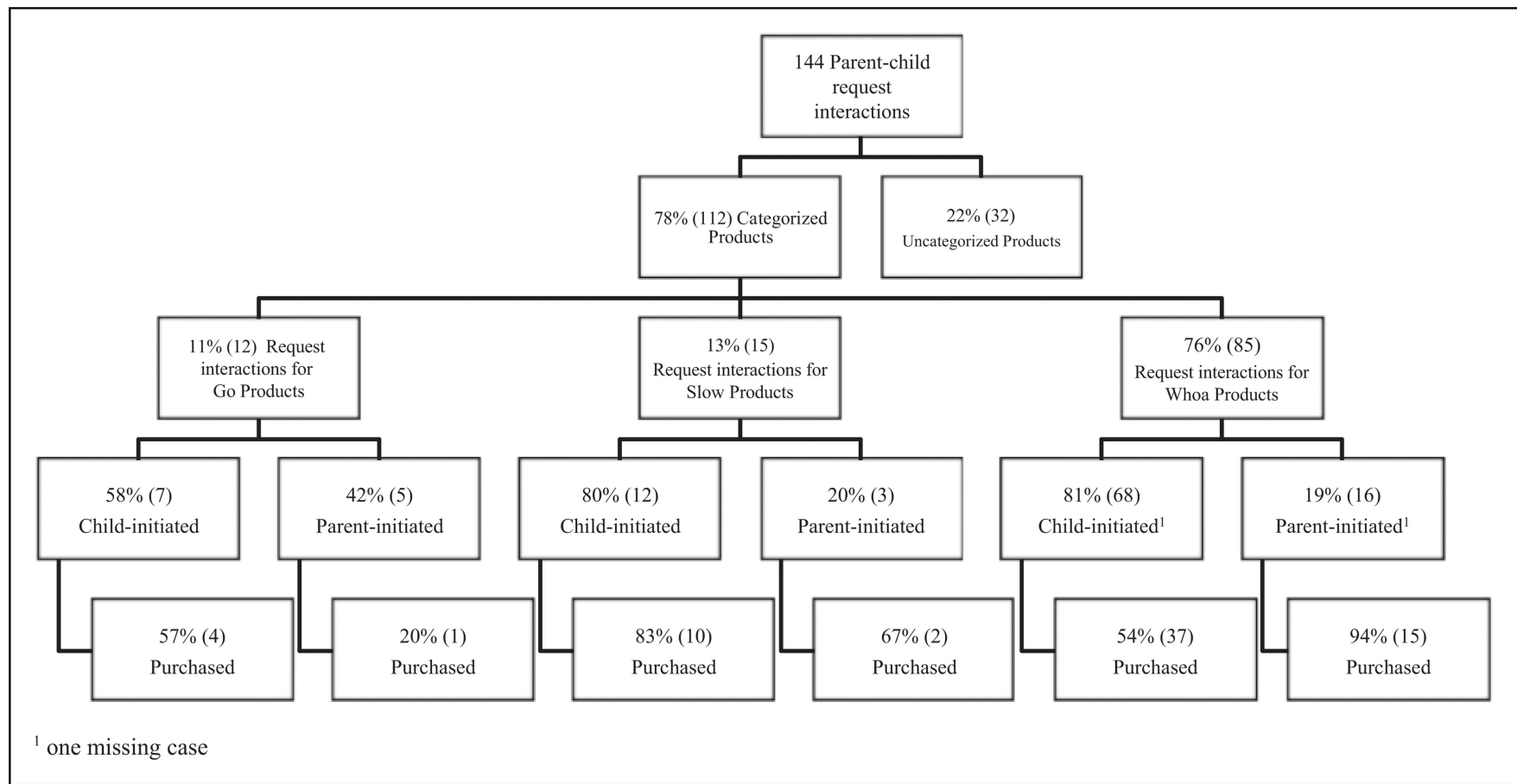

Figure 3.

All parent-child request interactions and purchases by product healthfulness and who initiated the request interaction. Superscript 1 represents one missing case.

Note. It should be noted that what is being reported is \% (n). 


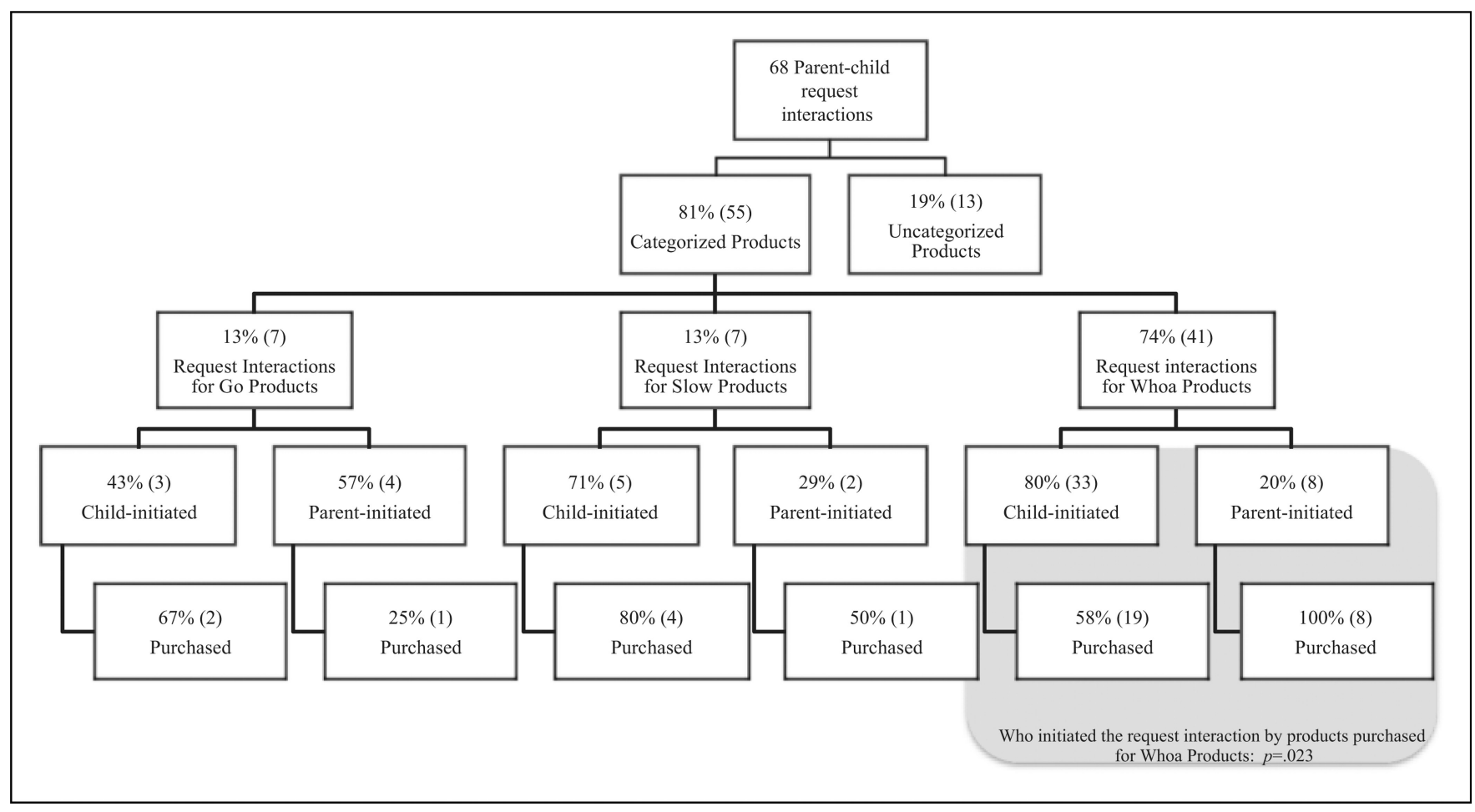

Figure 4.

Independent parent-child request interactions and purchases by product healthfulness and who initiated the request interaction.

Note. It should be noted that what is being reported is \% (n). 
Table 1

Child, Parent, Dyad, Shopping Trip, and Parent-Child Request Interaction Characteristics.

\begin{tabular}{lc}
\hline Characteristics & \% (n) or Mean (SD or Range) \\
\hline Child characteristics & $49 \%(49)$ \\
Female & $7.9(3.4)$ \\
Years of age & \\
Parent characteristics & $60 \%(60)$ \\
Female & $37.9(7.3)$ \\
Years of age & \\
Dyad characteristics & $36 \%(36)$ \\
Mother-daughter & $27 \%(27)$ \\
Father-son & $24 \%(24)$ \\
Mother-son & $13 \%(13)$ \\
Father-daughter & \\
Shopping trip characteristics & $83 \%(43)$ \\
Quick trip (vs. stock-up, special purpose) & $10(2-55)$ \\
Observation duration (in minutes) & \\
Parent-child request interaction characteristics & $1(0-6)$ \\
Average number of request interactions among all dyads & $68 \%(68)$ \\
Dyads with at least one request interaction & $2(1-6)$ \\
Average number of request interactions per dyad with at least one request interaction & $57 \%(57)$ \\
Dyads with at least one child-initiated request interaction & $27 \%(27)$ \\
Dyads with at least one parent-initiated request interaction & \\
\hline
\end{tabular}

Note. $S D=$ standard deviation. 